\title{
Bioreductive preparation of ACE inhibitors precursor $(R)$-2-hydroxy-4-phenylbutanoate esters: Recent advances and future perspectives
}

\author{
Guo-Chao Xu and Ye Ni*
}

\begin{abstract}
Optically active (R)-2-hydroxy-4-phenylbutanoate esters ((R)-HPBE) are key precursors for the production of angiotension-converting enzyme (ACE) inhibitors, which are important prescriptive drugs for preventing the formation of angiotensin II and lowering the blood pressure. The biocatalytic asymmetric reduction of ethyl 2-oxo-4phenylbutanoate (OPBE) to (R)-HPBE with carbonyl reductases has several advantageous attributes, including high enantioselectivity, mild reaction condition, high catalytic efficiency, and environmental benignity. An increasing number of OPBE reductases have been discovered owing to the drastic achievements in genomics, screening and evolution technologies, and process engineering. The potential of (R)-HPBE production process has also been intensively evaluated. This review covers recent progress on the bioreductive preparation of $(R)$-HPBE, especially on various screening approaches for the identification of OPBE reductases and their characterization.
\end{abstract}

Keywords: ACE inhibitors; Asymmetric reduction; Reductases; (R)-HPBE

\section{Introduction}

Optically active secondary alcohols, especially hydroxyl acids or hydroxyl acid esters, are important compounds for introducing chiral elements to pharmaceuticals, agricultural pesticides, and other fine chemicals [1-4]. (R)-2hydroxy-4-phenylbutanoate esters (OPBE), one class of chiral alcohols, are important precursors for the production of serials of angiotensin-converting enzymes (ACE) inhibitors, generally named as pril drugs (benazepril, cilazapril, quinapril, and ramipril), possessing (S)-homophenylalanine moiety as pharmacophore [5-7]. ACE (Kininase II, peptidyldipeptide hydrolase, EC 3.4.15.1) could catalyze the production of vasoconstrictor angiotensin II and inactivation of vasodilator bradykinin. Whereas inhibitors of ACE could prevent the formation of angiotensin II, hence decrease the blood pressure $[8,9]$. Along with the economic development, the incidence of hypertension is higher and younger which may induce stroke, heart failure, heart attack, and kidney failure. The annual revenues of prescriptive

\footnotetext{
* Correspondence: yni@jiangnan.edu.cn

The Key Laboratory of Industrial Biotechnology, Ministry of Education, School of Biotechnology, Jiangnan University, Wuxi 214122, China
}

antihypertensive drugs increased every year, with $\$ 45$ billion in total at the end of 2011 [10]. The ACE inhibitors drugs accounted for $10 \%$ among all the antihypertensive drugs. Hence, the preparation of their key chiral precursor $(R)-\mathrm{HPBE}$ is of special and increasingly interests.

Numbers of methods have been developed for the preparation of $(R)$-HPBE, including chemical, enzymatic, and chemoenzymatic approaches. According to the starting compounds, they can be divided into (1) enantioselective resolution of $\mathrm{rac}-\mathrm{HPBE}$, (2) asymmetric ene reduction, (3) asymmetric reduction of ene and carbonyl groups, (4) asymmetric reduction of OPBE, (5) hydrogenolysis, (6) enantioselective hydrolysis of rac-hydroxynitrile, etc. (Figure 1) [11-16]. The enantioselective resolution of rac-HPBE and rac-hydroxynitrile might represent effective approaches, however, limited to maximal yield of 50\% [12,17]. Asymmetric transfer hydrogenation $(\mathrm{ATH})$ of ketones plays an important role in asymmetric synthesis of chiral secondary alcohols [18-22]. Enantioselective hydrogenation of ethyl 2-oxo4-phenylbutanoate is likely one of the most economic and efficient method. Great efforts have been made to investigate the potential of this approach over the past 

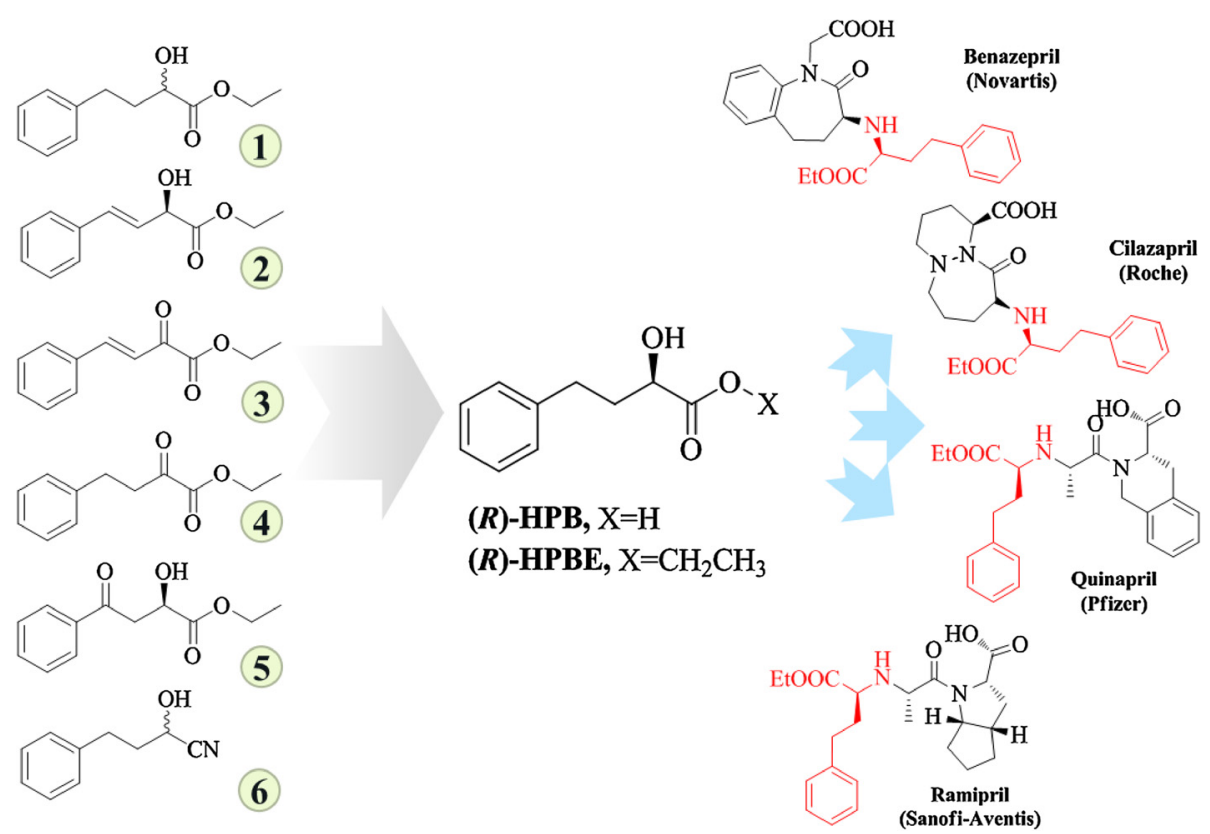

Figure 1 Various approaches for the synthesis of selected ACE inhibitors building blocks. (1) Enantioselective resolution of rac-HPBE, (2) asymmetric ene reduction, (3) asymmetric reduction of ene and carbonyl groups, (4) asymmetric reduction of OPBE, (5) hydrogenolysis, and (6) enantioselective hydrolysis of rac-hydroxynitrile.

few years. The highest enantioselectivity reported was $92 \%$ ee $(R)$ using 10,11-dihydrocinchonidine (DHCd) as the chiral modified, and $94 \%$ ee $(R)$ with the hydroxyl group in the DHCd modifier methylated. However, both cases were achieved using acetic acid as solvent, and under rigorous and commercially impractical conditions of high pressure $(100 \mathrm{bar})$ and high temperature $\left(400^{\circ} \mathrm{C}\right)$ hydrogen pretreatment of the $\mathrm{Pt} / \mathrm{Al}_{2} \mathrm{O}_{3}$ catalyst [22]. After optimization, this process could be carried out at mild reaction condition $\left(17^{\circ} \mathrm{C}\right.$ and 5.8 bar) resulting enantioselectivity of merely $91 \%$ [23]. Therefore, seeking effective, highly enantioselective, and practical chemical approaches to $(R)$-HPBE is still of significance.

Tremendous endeavors have been committed to the preparation of $(R)$-HPBE employing biocatalytic asymmetric reduction systems, which is a reliable, scalable, and straightforward route to chiral alcohols. Compared with classic chemical processes, the asymmetric reduction of OPBE into $(R)$-HPBE, or the reduction of 2-oxo-4phneylbutyrate (OPB) to $(R)$-2-hydroxy-4-phenylbutyrate $[(R)-\mathrm{HPB}]$ employing reductases and dehydrogenases (Figure 2) has several advantageous attributes, including high selectivity, high efficiency, mild reaction condition, and environmental friendless [24-27]. The complicated and chiral physiological structures endue the enzymes with relatively high chemo- and stereoselectivity and specificity. Various enzyme discovery and protein engineering tools have been proposed and proved, which would greatly shorten the developing period and increase the availability of robust enzymes. Several literatures on the biocatalytic asymmetric reduction for pharmaceuticals, protein engineering strategies for robust enzymes in chemical synthesis have been reviewed [28-32]. Also, various OPBE reductases have been successfully identified from natural samples or genome databases. The application potential and scalability of the biocatalytic processes have been systematically investigated. This mini-review was mainly focused on the discovery and properties of OPBE reductases. Future prospect of the application of bioreductive in preparation of optically pure (R)-HPBE synthesis was also discussed.

\section{Screening of microorganisms for bioreductive preparation of $(R)$-HPBE}

Due to the importance of $(R)$-HPBE as key chiral building blocks, searching for robust microorganisms has been extensively conducted as shown in Table 1. Some microorganisms, mainly yeasts, have been isolated from natural environment. Oda et al. screened 55 type culture yeasts from IFO and 499 isolated yeasts, among which two yeasts, Rhodotorula minuta IFO 0920 and Candida holmii KPY 12402, were identified with relatively high enantioselectivity. At $4.1 \mathrm{~g} \mathrm{~L}^{-1}$ OPBE loading, the ee and isolation yield could reach $90 \%$ and $58 \%$, respectively, using C. holmii KPY 12402 [33,34]. Kluyveromyces marxianus, Pichia pastoris, Pichia anomala, and Pichia angusta have also been tested in the asymmetric reduction of OPBE into $(R)-\mathrm{HPBE}$, and $P$. angusta displayed 


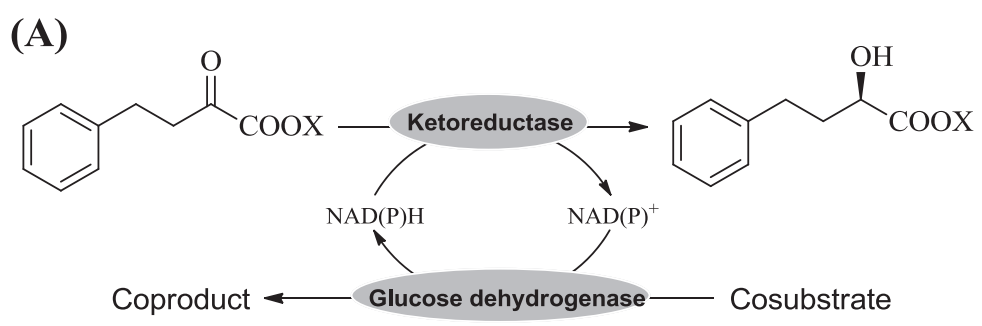

$\mathbf{X}=\mathrm{H}$, ethyl. Cosubstrate: glucose. Coproduct: gluconic acid.

(B)

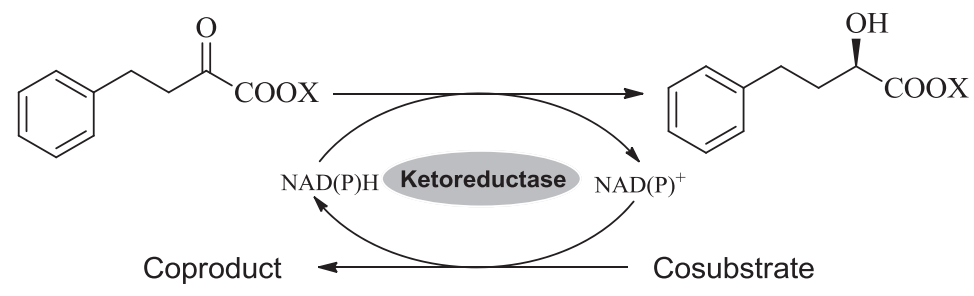

$\mathbf{X}=\mathrm{H}$, ethyl. Cosubstrate: isopropanol. Coproduct: acetone.

Figure 2 Asymmetric preparation of $(R)$-HPB derivatives employing oxidoreductases coupled with cofactor regeneration. (A) Enzymecoupled system. (B) Substrate-coupled system.

the best performance of $100 \%$ conversion and $81 \%$ ee [35]. Besides, Chadha et al. reported the preparation of (R)-HPBE from OPBE by using Daucus carota with excellent chemical yield (90\%) and ee (99\%) [36]. Chen et al. investigated the ability of 40 yeasts kept in CIOC (Chinese Institute of Organic Chemistry, Chinese Academy of Sciences) in the reduction of OPBE. Most of the candidate yeasts shown good (S)-preference (>99\%), while Candida boidinii CIOC21 was proved to be $(R)$-preference. As much as $2.0 \mathrm{~g} \mathrm{~L}^{-1}$ OPBE could be asymmetrically reduced into $(R)$-HPBE with $99.7 \%$ ee and $95.1 \%$ yield [37]. Target reaction oriented enrichment and screening of microorganisms have also been carried out in our laboratory, and one yeast strain Candida krusei SW2026 displayed desirable ee (99.7\%) and yield (95.1\%) in aqueous phase at $2.5 \mathrm{~g} \mathrm{~L}^{-1}$ of OPBE [17]. The highest record of OPBE loading in microbial system was achieved with Bacillus pumilus Phe-C3 by He and coworkers. At $6.2 \mathrm{~g} \mathrm{~L}^{-1}$ of
OPBE and $12 \mathrm{~g} \mathrm{cdw} \mathrm{L}^{-1}$ catalyst, 95.3\% OPBE could be reduced with $97.1 \%$ ee [38].

\section{Discovery and characterization of OPBE reductases}

Although many wild-type microbial cells could catalyze the asymmetric reduction of OPBE into $(R)-\mathrm{HPBE}$, their industrial applications are limited by a number of disadvantageous. The expression level and enzymatic properties of OPBE reductases are often undesirable in parent strains [28]. Additionally, there might exist several enzymes with variable or opposite stereospecificity that could result HPBE with compromised chirality [39]. And the fermentation conditions of wild-type strains are usually strict and time-consuming. Studies on the discovery and properties of isolated OPBE reductases are therefore of special interests to prompt the biocatalytic preparation of chiral (R)-HPBE.

Table 1 Asymmetric reduction of OPBE into (R)-HPBE employing microorganisms

\begin{tabular}{|c|c|c|c|c|c|}
\hline Entry & Strains & OPBE loading $\left[\mathrm{g} \mathrm{L}^{-1}\right]$ & $e e[\%]$ & Yield[\%] & Reference \\
\hline 1 & Candida krusei SW2026 & 2.5 & 99.7 & 95.1 & {$[17]$} \\
\hline 2 & Bacillus pumilus Phe-C3 & 6.2 & 97.1 & 91 & {$[37]$} \\
\hline 3 & Candida boidinii $\mathrm{ClOC} 21$ & 2 & 99 & 92 & {$[36]$} \\
\hline 4 & Baker's yeast & 1 & 92 & 90 & {$[38]$} \\
\hline 5 & Candida holmi & 4.1 & 90 & 58 & [33] \\
\hline 6 & Pichia angusta & 1.4 & 81 & 99 & [34] \\
\hline 7 & Pichia pastoris & 1 & 95 & 99 & [7] \\
\hline
\end{tabular}




\section{Enzyme discovery strategies}

Alongside the revolution of biotechnologies, a variety of tools are available for the quick screening and identification of biocatalysts. Several comprehensive reviews discussed the discovery and engineering tools developed to obtain naturally evolved or tailor-made enzymes with enhanced properties for chemical synthesis [29,30,40]. In the case of microbial strains isolated from natural environment, enzymes could be discovered through protein purification, insertional mutation, chromosome walking, shotgun library, etc. With regard to vast amount of genome information, genome hunting and genome database mining are two direct and time-saving strategies.

\section{Protein purification}

For a long time, purification of target enzymes from wildtype strains has been the dominant approach for enzyme discovery [41]. Through several purification steps, such as ammonium sulfate precipitation, ion exchange chromatography, hydrophobic chromatography, affinity chromatography and gel chromatography, and pure or partially purified enzymes could be harvested. After characterization with protein NMR of terminal peptide and MS, the encoding gene sequence of target enzymes could be acquired. Various carbonyl reductases of different origins (microorganisms and plant tissues) have been discovered through microorganism isolation and protein purification. A robust carbonyl reductase was purified from Adzuki bean, with high enantioselectivity ( $>99 \% e e$ ) and tolerance to $\alpha$-chloroacetophenone (0.2 M) [42].

\section{Insertional mutation}

This strategy utilizes a proper transposon to insert randomly into the genome sequence and disturb the normal properties or phenotypes of the strains. Through screening for mutants exhibiting expected changes and sequencing, the target genes could be identified. Various novel enzymes and pathways have been discovered employing this method, such as two novel genes pao and sap from Pseudomonas sp. Strain HZN6, coding for 6-hydroxy-L-nicotine oxidase and $\mathrm{NADP}^{+}$-dependent 3-succinoylsemialdehyde-pyridine dehydrogenase in the catabolism of nicotine [43].

\section{Chromosome walking}

Based on conserved motif of certain enzymes, chromosome walking provided a new method to identify functional enzymes [44]. A functional P450 monooxygenase from Rhodococcus sp. ECU0066 was identified by chromosome walking by several rounds of PCR, with capability in the enantioselective oxidation of sulfides [45].

\section{Shotgun library}

Compared with other strategies, shotgun library was much more common and easier to operate in discover functional enzymes. Through construction the subclones of the genome in proper fragment length, a shotgun library could be developed. Many enzymes were identified using this approach. For example, Zhang and coworkers successfully cloned a novel arylamidase encoding gene from Paracoccus sp. strain FLN-7 which could hydrolyze amide pesticides [46].

\section{Genome hunting}

In the case of available genome data, genome hunting could be adopted to identify the target enzymes by cloning all of the potential genes from this single genome. Through genome hunting, $\mathrm{Ni}$ and coworkers heterogeneously expressed 13 reductases genes from Bacillus sp. ECU0013. Among them, the FabG (a $\beta$-ketoacyl-ACP reductase) exhibited high efficiency in the asymmetric reduction of $620 \mathrm{~g} \mathrm{~L}^{-1} \mathrm{OPBE}$ to $(S)$-HPBE, with no addition of external expensive cofactor and 99\% ee. Although the product configuration is not the desired one, it could be converted to $(R)$ - HPBE through one-step configuration inversion [47].

\section{Genome database mining}

Another effective and promising strategy for quick discovery of suitable enzymes is genome database mining for homologous protein sequences of targeted enzymes. Owing to the revolution of sequencing technology, there are 58,117 sequencing projects (including 6,649 complete projects, 23,552 permanent drafts, 26,572 incomplete projects, and 1,404 targeted projects) in genome online database as of September 2014, providing massive data on protein-coding genes [48]. The selection of reported enzymes as probe and the choice of candidate proteins in database with moderate identity are the two key factors for the successful identification of new enzymes. The sequence of several known ethyl 4-chloro3-oxobutanate (COBE) reductases was regarded as probes to search for novel enzymes in GenBank, resulting in an excellent reductase from Streptomyces coelicolor out of ten candidates for the synthesis of optically pure ethyl (S)-4-chloro-3-hydroxybutanoate, a chiral building blocks for HMG-CoA reductase inhibitors, with a stunning high productivity of $609 \mathrm{~g} \mathrm{~L}^{-1}$ day $^{-1}$ [49].

\section{Selected OPB(E) redutases}

As shown in Table 2, a number of OPBE reductases have been discovered using above mentioned strategies. Most of the OPBE reductases are NADPH-dependent. A phenylacetaldehyde reductase (PAR) was purified from Rhodococcus ST-10 [50]. After amino-acid sequence analysis, the recombinant PAR was expressed in Escherichia coli [51]. One PAR mutant (HAR-1) could asymmetrically reduce $195 \mathrm{~g} \mathrm{~L}^{-1} \mathrm{OPBE}$ to $(R)$ - HPBE with $99 \%$ ee and $89 \%$ isolation yield [52]. The shotgun library of 
Table 2 Enzymatic properties of oxidoreductases for producing (R)-HPB derivatives

\begin{tabular}{|c|c|c|c|c|c|c|c|c|c|c|c|c|c|c|c|c|}
\hline Enzyme & Source strain & $\begin{array}{l}\text { Accession } \\
\text { no }\end{array}$ & $\begin{array}{l}\text { Discovery } \\
\text { strategy }\end{array}$ & $\begin{array}{l}\text { Length } \\
\text { [aa] }\end{array}$ & Cofactor & Family $^{a}$ & $\begin{array}{l}\text { Specific activity } \\
{\left[\mathrm{Ug}^{-1}\right]}\end{array}$ & $\begin{array}{l}K_{\mathrm{m}} \\
{[\mathrm{mM}]}\end{array}$ & $V_{\max }\left[\mathrm{U} \mathrm{mg}^{-1}\right]$ & $\begin{array}{l}\text { Opt. } \\
\text { temp. } \\
{\left[{ }^{\circ} \mathrm{C}\right]^{b}}\end{array}$ & $\begin{array}{l}\text { Sub. } \\
\text { loading } \\
{\left[g^{-1}\right]}\end{array}$ & $\begin{array}{l}\text { Time } \\
\text { [h] }\end{array}$ & $\begin{array}{l}e e \\
{[\%]}\end{array}$ & $\operatorname{TTN}^{c}$ & $\begin{array}{l}\text { STY } \\
{\left[\mathrm{g} \mathrm{L}^{-1} \mathrm{~d}^{-1}\right]^{d}}\end{array}$ & Reference \\
\hline Ypr1p & S. cerevisae & AHY75323.1 & $\begin{array}{l}\text { Genome } \\
\text { hunting }\end{array}$ & 312 & $\mathrm{NADPH}$ & AKR & $n^{e}$ & nd & nd & nd & 2.0 & nd & 87 & nd & nd & [54] \\
\hline lols & B. subtilis & CAB16014.1 & $\begin{array}{l}\text { Database } \\
\text { mining }\end{array}$ & 310 & NADPH & AKR & 5.1 & 2.61 & 4.18 & 30 & 330 & 12 & $>99$ & 32039 & 660 & [57] \\
\hline CgKR2 & C. glabrata & CAG61069.1 & $\begin{array}{l}\text { Database } \\
\text { mining }\end{array}$ & 311 & NADPH & AKR & 2.4 & 0.1 & 18.5 & 45 & 206 & 6 & 99 & $n c^{f}$ & 700 & [59] \\
\hline $\mathrm{NcCR}$ & $\begin{array}{l}\text { Neurospora } \\
\text { crassa }\end{array}$ & XM_954278 & $\begin{array}{l}\text { Genome } \\
\text { hunting }\end{array}$ & 331 & NADPH & AKR & 1.6 & nd & nd & 40 & 2.0 & 24 & 80 & 20 & 2 & [56] \\
\hline CgKR1 & C. glabrata & CAG58832.1 & $\begin{array}{l}\text { Database } \\
\text { mining }\end{array}$ & 352 & NADPH & MDR & 23.1 & nd & nd & nd & 412 & 24 & 98.1 & $n c^{f}$ & 358 & [58] \\
\hline YOL151w & S. cerevisiae & CAA99172.1 & $\begin{array}{l}\text { Genome } \\
\text { hunting }\end{array}$ & 342 & NADPH & MDR & nd & nd & nd & nd & 1 & 48 & 99 & 10 & 0.5 & [55] \\
\hline PpADH & $\begin{array}{l}\text { Paracoccus } \\
\text { pantotrophus DSM } \\
11072\end{array}$ & EU427522 & $\begin{array}{l}\text { Shotgun } \\
\text { library }\end{array}$ & 262 & $\mathrm{NADH}$ & SDR & 0.0043 & nd & nd & nd & 5 & 24 & 99 & 24.3 & 5 & [53] \\
\hline PAR & $\begin{array}{l}\text { Rhodococcus sp. } \\
\text { ST-10 }\end{array}$ & AB190261 & Purification & 348 & $\mathrm{NADH}$ & MDR & nd & nd & nd & nd & 195 & 24 & 99 & 947 & 174 & [52] \\
\hline YiaE & E. coli $\mathrm{K} 12$ & BAE77742.1 & $\begin{array}{l}\text { Genome } \\
\text { hunting }\end{array}$ & 324 & NADPH & HAD & 18 & 7.2 & 24.6 & 45 & 20 & 24 & 99 & $n c^{f}$ & 20 & [60] \\
\hline
\end{tabular}

${ }^{\mathrm{a}}$ Enzyme families, AKR aldo-keto reductase, HAD 2-hydroxyacid dehydrogenase, SDR short chain dehydrogenase/reductase, MDR medium chain dehydrogenase/reductase. ${ }^{\mathrm{b}}$ Optimal temperature. ${ }^{\mathrm{d}}$ total turnover number

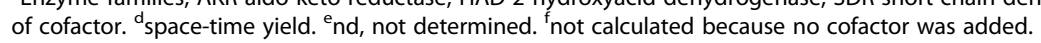


Paracoccus pantotrophus DSM 11072 was developed to search for enzyme with OPBE reduction activity, resulting in the novel enzyme PpADH with $99 \%$ ee $(R)$ at $5 \mathrm{~g} \mathrm{~L}^{-1}$ OPBE [53]. Through genome hunting, Ypr1p and YOL151w were identified from Saccharomyces cerevisiae with $87 \%$ and $99 \%$ ee $(R)$, respectively [54,55]. NcCR was cloned from Neurospora crassa with $1.6 \mathrm{U} \mathrm{mg}^{-1}$ specific activity and $80 \%$ ee $(R)$ [56]. Employing genome database mining strategy, three OPBE reductases (IolS, CgKR1, and CgKR2) were discovered from genome database [57-59]. Both CgKR1 and CgKR2 were cloned from Candida glabrata, with specific activities of 23.1 and $2.4 \mathrm{U} \mathrm{mg}^{-1}$ and ee values of $98.7 \%$ and $99 \%$, respectively. CgKR1 was stable enough to tolerate as high as $412 \mathrm{~g} \mathrm{~L}^{-1} \mathrm{OPBE}$, while CgKR2 could completely reduce $206 \mathrm{~g} \mathrm{~L}^{-1}$ OPBE into $(R)$-HPBE (>99\% ee) with $700 \mathrm{~g} \mathrm{~L}^{-1}$ day $^{-1}$ space-time yield. In our previous study, IolS could tolerate $330 \mathrm{~g} \mathrm{~L}^{-1}$ OPBE with $99 \%$ ee $(R)$. The specific activity of IolS was $5.1 \mathrm{U} \mathrm{mg}^{-1}$ [57]. In addition, $(R)$-2-hydroxy-4-phenylbutyrate $((R)-\mathrm{HPB})$ is also a precursor for ACE inhibitors and could be synthesized through stereospecific reduction of 2-oxo-4-phenylbutyrate $(\mathrm{OPB})$ as illustrated in Figure 1. One hydroxy acid dehydrogenase (YiaE) gene was cloned from E. coli $\mathrm{K} 12$, which could asymmetrically reduce $20 \mathrm{~g} \mathrm{~L}^{-1} \mathrm{OPB}$ into its corresponding hydroxy acid, $(R)-\mathrm{HPB}$, in $>99 \%$ ee within $24 \mathrm{~h}$. The specific activity was determined to be $20 \mathrm{U} \mathrm{mg}^{-1}$, the optimum temperature was $45^{\circ} \mathrm{C}$ [60].

Table 2 Enzymatic properties of oxidoreductases for producing $(R)$-HPBE from OPBE.

\section{Classification of $\mathrm{OPB}(\mathrm{E})$ reductases}

According to the amino acid sequence and metal-ion dependency, the carbonyl reductases could be divided into short-chain dehydrogenase/reductase (SDR), mediumchain dehydrogenase/reductase (MDR), long-chain dehydrogenase/reductase (LDR), and aldo-keto reductase (AKR) [61-63]. Key motif search in online databases (SDR, http://www.sdr-enzymes.org/; MDR, http://www.bioinfo. ifm.liu.se/services/mdr/; AKR, http://www.med.upenn.edu/ akr/) reveals that PpADH belongs to SDR family, CgKR1, YOL151w, and PAR belong to MDR family, while Ypr1p, CgKR2, NcCR, and IolS are members of AKR. PAR is the only zinc-dependent carbonyl reductase. Tyr-Lys-Ser, CysHis-Asp, and His-Tyr-Lys are common catalytic triads for SDR, MDR, and AKR, respectively $[21,64,65]$. Reductase YiaE from $E$. coli with reduction activity in the conversion of OPB into (R)-HPB was classified into 2-hydroxyacid dehydrogenase family (Table 2 ).

Regarding to crystal structure information of the OPBE reductases, protein crystal structure of IolS from Bacillus subtilis is the only one deposited in the PDB database (PDB accession no. 1PYF) [65]. In the structure of IolS, the most common fold, $(\beta / \alpha)_{8}$ barrel motif, seems to form a barrel conformation. The cofactor
$\left(\mathrm{NAD}(\mathrm{P})^{+} / \mathrm{NAD}(\mathrm{P}) \mathrm{H}\right)$ is bound at the $\mathrm{C}$-terminal of internal $\beta$-barrel, extending in an extended conformation from the center of the barrel with no intra-molecular hydrogen bonds. Besides to the conserved folding, the catalytic tyrosine at 58 sites acts as an acid in the reduction reaction. The acidity is enhanced through a hydrogen bond with the lysine of catalytic triad, which also in turn forms a salt bridge with the aspartate. In the apo form, the hydrogen bond between catalytic Tyr58 and Lys 84 was $3.25 \AA$. When $\mathrm{NADP}^{+}$binds, the distance between the lysine $\zeta$-amino group and the tyrosine hydroxyl is extended to $4.26 \AA$, which causes the disruption of this hydrogen bond due to a shift of Tyr58 towards the $\mathrm{NADP}^{+}$. Two additional amino acids Asp51 and Lys84, which complete the catalytic triad by activating the phenolic proton on the tyrosine, also present in IolS. The interactions between both residues in the holo conformation are mediated by hydrogen bonds with a water molecule.

Since three other OPBE reductases (Ypr1p, CgKR2, and $\mathrm{NcCR}$ ) are also potential AKR members, the amino acid sequence alignment of them is shown in Figure 3. Four AKR members shared similar backbones, although the sequence identity is relatively low $(<50 \%)$. The catalytic tyrosine and aspartate are quite conserved in all four OPBE reductases, while the lysines are located around the conserved site of IolS. Most of the AKR are NADP-dependent and share the similar loop at the Cterminal, with 2'-phosphate tightly bound via three salt bridges with Arg227, Arg282, and Lys214 and a hydrogen bond with the side-chain of $G \ln 286$.

\section{Bioprocess engineering for improved efficiency}

For a biocatalytic process, several parameters are critical to evaluate the efficiency, including space-time yield, total turnover number (TTN) of cofactor or reductase, productivity, etc. However, hydrophobic OPBE could cause the deactivation of enzymes and often requires longer reaction time to achieve a higher conversion rate [57]. Consequently, the efficiency is usually at low level. Various process engineering strategies have been developed to solve the problems and improve the efficiency in the preparation of chiral secondary alcohols employing reductases.

\section{Cofactor regeneration}

To achieve complete conversion of OPBE by carbonyl reductases, stoichiometric amount of reducing cofactors is usually required. The high cost of cofactors is one of the main hurdles for the wide application of bioreductive preparation. Introduction of proper cofactor cycling systems could reduce the addition of expensive cofactors and promote reaction towards the synthesis of product. Numerous cofactor regeneration systems have been 


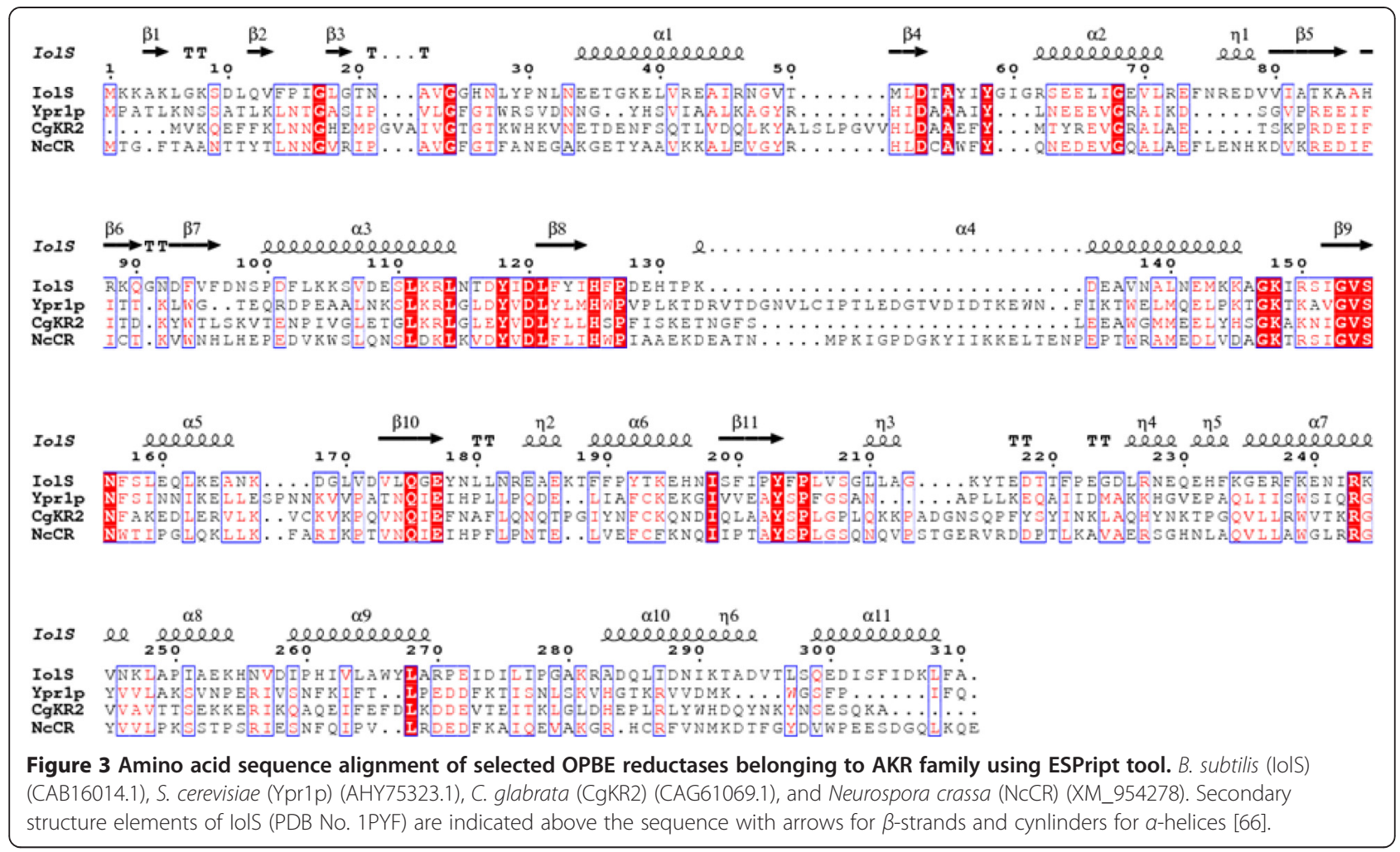

developed and systematical summarized in recent reviews [67-69]. In general, there are three approaches to regenerate cofactors, including substrate-coupled, enzyme-coupled, and reaction-internal regeneration accomplished by enzymatic, chemical, photochemical, or electrochemical reagents. Several principles need to be considered in order to select an appropriate regeneration system as following:

1. Catalysts as well as cosubstrates should be commercially available or easily producible.

2. Product formation should be thermodynamically as well as kinetically favored and has no interference with the enzymes or with the subsequent isolation of desired product.

3. Regeneration should be practical and inexpensive and stable over a long period of time.

In the view of all these factors, the feasibility of glucose dehydrogenase, formate dehydrogenase, and isopropanol-coupled ketoreductase technologies have been proven. Formate dehydrogenase, however, exhibited low recycling efficiency on $\mathrm{NADP}^{+}$. Glucose dehydrogenase and isopropanol-coupled systems have been applied in the enantioselective synthesis of $(R)$ HPB derivatives. By using glucose dehydrogenases from B. subtilis, the TTN of $\mathrm{NADP}^{+}$could reach as much as 32,039 in the asymmetric reduction of $330 \mathrm{~g} \mathrm{~L}^{-1}$ OPBE employing IolS from $B$. subtilis under assistance of $0.05 \mathrm{mM} \mathrm{NADP}^{+}$(Figure 2A). PAR from Rhodococcus sp. ST-10 is a reductase with isopropanol oxidation activity. Itoh and coworkers adopted the substrate-coupled strategy in the preparation of $(R)$-HPBE with PAR (Figure 2B). Almost $195 \mathrm{~g} \mathrm{~L}^{-1} \mathrm{OPBE}$ was completely reduced, and the TTN of $\mathrm{NAD}^{+}$was 947. Isopropanol could not only work as cosubstrate, but also as cosolvent to increase the solubility of OPBE.

\section{Solvent engineering}

Solvents constitute the microenvironment around the biocatalysts. By introducing organic solvents, ionic liquids, supercritical fluids, and glycerol into the biocatalytic reduction systems, not only the toxicity of substrate/product to hydrophilic biocatalysts could be alleviated, but also their spontaneously hydrolysis and volatilization could be relieved. Among them, organic/ aqueous biphasic system was the most common used approach as illustrated in Figure 4A. The key of this system was to find a good suitable and biocompatibility solvents, which could balance the influence on the activity and enantioselectivity of enzymes and the partition behavior of substrate and product. C. krusei SW2026 was proved to display $99.7 \%$ ee $((R)-\mathrm{HPBE})$ and $95.1 \%$ yield at $2.5 \mathrm{~g} \mathrm{~L}^{-1} \mathrm{OPBE}$ in aqueous system [17]. As substrate loading increased to $20 \mathrm{~g} \mathrm{~L}^{-1}$, the ee and yield were reduced to $87.5 \%$ and $45.8 \%$, respectively, which was 


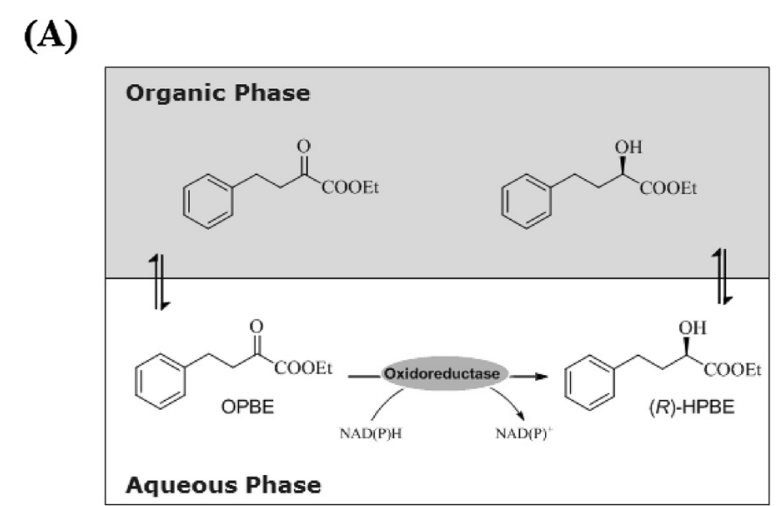

(B)

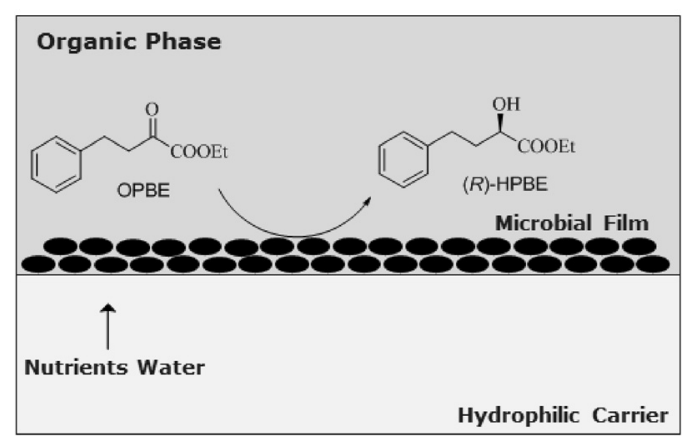

Figure 4 Scheme of bioreductive preparation of $(R)$-HPBE in organic solvent/aqueous biphasic system (A) and an interface bioreactor (B).

caused by the higher amount of toxic OPBE. Based on the solvent polarity, ten organic solvents with different $\log P$ values ranging from 0.28 to 7.7 were selected. Dibutyl phthalate $(\log P=5.4)$ showed the highest biocompatibility and proper partition coefficient for OPBE and HPBE. Compared with aqueous system, less time was required to reach higher conversion, resulting in 95.0\% ee and $92.5 \%$ isolation yield. This dibutyl phthalate/aqueous biphasic system could not only migrate the substrate toxicity effect from enzymes/cells, but also force the reaction equilibrium towards the reduction of OPBE by accumulating $(R)$-HPBE in the organic phase.

\section{Substrate feeding}

To realize a high substrate loading, substrate feeding at batches is an effective strategy to reduce the of substrate inhibition. A much higher catalytic efficiency could be achieved by substrate-feeding operation. In our studies using 1-L aqueous/octanol biphasic system, $30 \mathrm{~g}$ OPBE was fed once per hour for ten times (330 $\mathrm{g}$ in total). After $12 \mathrm{~h}$ of reaction, substrate conversion rate of $>99 \%$ and space-time yield of $660 \mathrm{~g} \mathrm{~L}^{-1}$ day $^{-1}$ were obtained at $330 \mathrm{~g} \mathrm{~L}^{-1}$ OPBE [57]. The substrate loading was 1.6 times higher than that of the highest record reported so for. Additionally, a S/C ratio of 31.7 was attained, ranking the highest catalyst yield in the asymmetric reduction of OPBE, which was 0.02-4.12 as reported [59].

\section{Other processes}

To alleviate the toxicity of hydrophobic OPBE/HPBE, interface bioreactors have been established. It is a biotransformation device between a hydrophilic carrier and a hydrophobic organic solvent as shown in Figure 4 [34]. In this system, the biocatalyst was immobilized on the carrier surface between the hydrophilic and hydrophobic solvents. Interestingly, the recycling of cofactors could proceed smoothly, and the product separation was relatively easier than that for aqueous systems.

The smart control of OPBE concentration in the reaction medium could also be achieved by adsorbing the substrate on hydrophobic resins (Figure 4B). D'Arrigo and coworkers proved that $\mathrm{XAD}^{\mathrm{ma}} 1180$, a polystyrenic adsorbent selected among several Amberlite resins, was effective in controlling the OPBE amount presented in water phase. OPBE $\left(1 \mathrm{~g} \mathrm{~L}^{-1}\right)$ could be reduced asymmetrically employing Pichia pastoris with 99\% conversion and $95 \%$ ee $(R)$ [7]. Continuous batch reactor (CBR) was established combining the biotransformation and OPBE/ HPBE adsorption. In the CBR unit, the bioreduction of

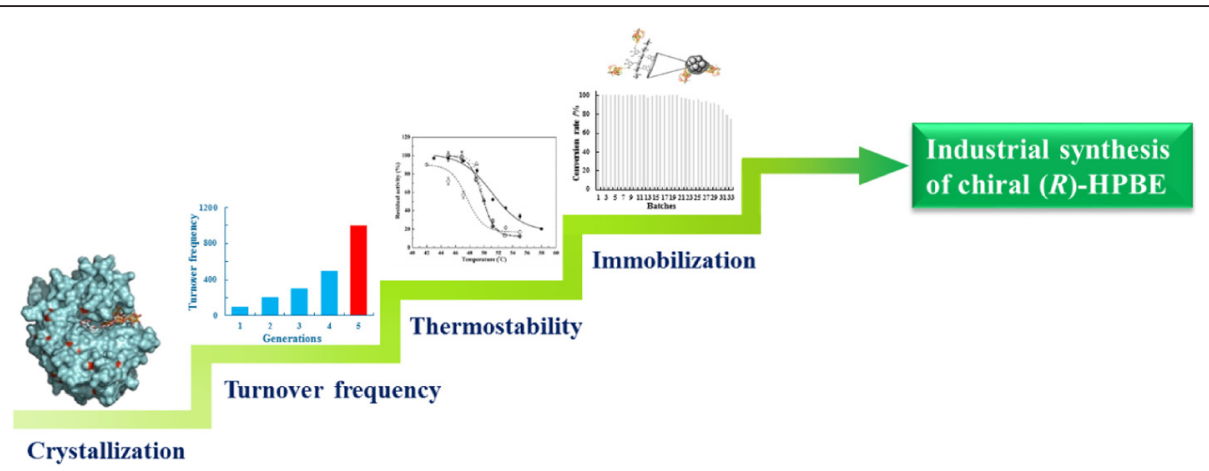

Figure 5 Further perspectives on the engineering of $\mathrm{OPB}(\mathrm{E})$ reductases for industrial synthesis of $(R)$-HPBE. 
OPBE was carried out for $48 \mathrm{~h}$ at a substrate-feeding flow rate of $1 \mathrm{~mL} \mathrm{~min}^{-1}$, resulting $95.1 \% e e(R)$ and conversion rate of $25 \%$.

\section{Prospects}

Biocatalytic preparation of chiral alcohol is gaining momentum. Due to its high enantioselectivity, bioreductive preparation of chiral $(R)$-HPBE has been regarded as one of the most promising approaches. There are enormous difference between natural environment (i. e., cytosolic conditions) and industrial environment. Free enzymes might face hash environment, such as molar scale reactants and increased hydrophobicity instead of millimolar reagents and physiological aqueous environment. To become an efficient tool in large-scale synthesis of $(R)$-HPBE, OPBE reductases should display the following properties: (1) $\geq 100 \mathrm{~g} \mathrm{~L}^{-1}$ substrate loading, (2) $\leq 5 \mathrm{~g} \mathrm{~L}^{-1}$ biocatalyst loading ( $\geq 20$ substrate to catalyst ratio), (3) $\geq 98 \%$ conversion rate, $(4) \leq 24 \mathrm{~h}$ reaction time, and (5) $\geq 99 \%$ ee $[21,28]$. Although several biocatalytic reduction systems could reach high substrate loading, enantioselectivity, and conversion, the biocatalyst loadings are still at relatively high and the S/C ratio is relatively low, which would hinder the product separation procedure.

Aiming at the industrial synthesis of $(R)$-HPBE, the biocatalytic procedure should be further engineered (Figure 5). In PDB database, extremely limited information on the crystal structure of OPBE reductases is available. The protein structure could broaden the knowledge of biocatalytic mechanism and provides guidance for further protein engineering. The catalytic efficiency (turnover frequency, $k_{\text {cat }}$ ) also remained to be improved to decrease the catalyst loading. As a robust industrial biocatalyst, thermostability and operational stability should also be high enough to tolerate rigorous reaction conditions. As shown in Table 2, most of the OPBE reductases are mesophilic enzymes, with optimum temperature of less than $45^{\circ} \mathrm{C}$. Since the oxidoreduction reaction is cofactor-dependent, the cofactor engineering of bioreduction systems would fasten the reaction and decrease the addition of expensive cofactors. Importantly, reuse of the biocatalysts through proper immobilization strategies could also reduce the cost and simplify the product separation from reaction mixture.

\section{Conclusion}

Biocatalytic stereoselective reduction for (R)-2-hydroxy4-phenylbutanate esters is gaining momentum. Various OPBE reductaes have been identified and some of them have indicated promising potential for practical manufacture of (R)-HPBE. The discovery strategies for OPBE reductases and bioprocessing engineering strategies have been reviewed. Further development of bioreductive preparation of (R)-HPBE will require the continued mining and designing industrially useful enzymes and elaboration of process engineering.

\section{Competing interests}

The authors declare that they have no competing interests.

\section{Authors' contributions}

GCX wrote this manuscript. YN contributed general advice and edited the manuscript. Both authors read and approved the final manuscript.

\section{Acknowledgements}

We are grateful to the Natural Science Foundation of China (21276112), National Basic Research and Development Program of China (2011CB710800), and New Century Excellent Talents in University (NCET11-0658) for the financial support of this research.

Received: 12 November 2014 Accepted: 16 February 2015 Published online: 31 March 2015

\section{References}

1. Patel RN (2006) Biocatalysis: Synthesis of chiral intermediates for drugs. Curr Opin Drug Disc Dev 9:741-764

2. Tao JH, Xu JH (2009) Biocatalysis in development of green pharmaceutical processes. Curr Opin Chem Biol 13:43-50

3. Magano J, Dunetz JR (2012) Large-scale carbonyl reductions in the pharmaceutical industry. Org Process Res Dev 16:1156-1184

4. Reetz MT (2013) Biocatalysis in organic chemistry and biotechnology: Past, Present, and Future. J Am Chem Soc 135:12480-12496

5. Iwasaki G, Kimura R, Numao N, Kondo K (1989) A practical and diastereoselective synthesis of angiotensin converting enzyme inhibitors. Chem Pharm Bull 37:280-283

6. Bradshaw CW, Wong CH, Hummel W, Kula MR (1991) Enzyme-catalyzed asymmetric synthesis of (S)-amino-4-phenylbutanoic acid and (R)-2-hydroxy4-phenylbutanoic acid. Bioorg Chem 19:29-39

7. D'Arrigo P, Pedrocchi-Fantoni G, Servi S (2010) Chemo-enzymatic synthesis of ethyl (R)-2-hydroxy-4-phenylbutyrate. Tetrahedron Asymmetry 21:914-918

8. Parmley WW (1998) Evolution of angiotensin-converting enzyme inhibition in hypertension, heart failure, and vascular protection. Am J Med 105:27S-31s

9. Maruyama S, Nakagomi K, Tomizuka N, Suzuki H (1985) Angiotensin Iconverting enzyme inhibitor derived from an enzymatic hydrolysate of casein. II. Isolation and bradykinin-potentiating activity on the ileum of rats. Agric Biol Chem 49:1405-1409

10. Crandall MA (2007) The world cardiovascular drug market, $2^{\text {nd }}$ edition, Kalorama Information, SKU:KLI1397872.

11. Baskar B, Pandian NG, Priya K, Chadha A (2004) Asymmetric reduction of alkyl 2-oxo-4-arylbutanoates and -but-3-enoates by Candida parapsilosis ATCC 7330: assignment of the absolute configuration of ethyl 2-hydeoxy-4(p-methylphenyl)but-3-enoate by ${ }^{1} \mathrm{H}$ NMR. Tetrahedron Asymmetry 15:3961-3966

12. Huang SH, Tsai SW (2004) Kinetic resolution of (R, S)-ethyl 2-hydeoxyl-4phenylbutyrate via lipase-catalyzed hydrolysis and transesterification in isooctane. J Mol Catal B: Enzyme 28:65-69

13. Zhu LF, Meng QH, Fan WZ, Xie XM, Zhang ZG (2010) Direct asymmetric hydrogenation of 2-oxo-4-arylbut-3-enoic acids. J Org Chem 75:6027-6030

14. Aldea R, Alper $H$ (1998) Hydrogenation of the carbonyl group in $a-$ kektoesters and a-ketoamides catalyzed by ruthenium clay. J Org Chem 63:9425-9426

15. Rodrigues JAR, Milagre HMS, Milagre CDF, Moran PJS (2005) A highly enantioselective chemoenzymatic synthesis of syn-3-amino-2-hydroxy esters: Key intermediates of taxol side chain and phenylnorstatine. Tetrahedron Asymmetry 16:3099-3106

16. Meng QH, Zhu LF, Zhang ZG (2008) Highly enantioselective sequential hydrogenation of ethyl 2-oxo-4-arylbut-3-enoate to ethyl 2-hydroxy-4arylbutyrate. J Org Chem 73:7209-7212

17. Zhang W, Ni Y, Sun ZH, Zheng P, Lin WQ, Zhu P, Ju NF (2009) Biocatalytic synthesis of ethyl (R)-2-hydroxy-4-phenylbutyrate with Candida krusei SW226: a practical process for high enantiopurity and product titer. Process Biochem 44:1270-1275

18. Noyori R (2003) Asymmetric catalysis: Science and opportunities. Adv Synth Catal 345:15-32 
19. Noyori R, Yamakawa M, Hashiguchi S (2011) Metal-ligand bifuctional catalysis: a nonclassical mechanism for asymmetric hydrogen transfer between alcohols and carbonyl compounds. J Org Chem 66:7931-7944

20. Hall M, Bommarius AS (2011) Enantioenriched compounds via enzymecatalyzed redox reactions. Chem Rev 111:4088-4110

21. Hollmann F, Arends IWCE, Holtmann D (2011) Enzymatic reductions for the chemist. Green Chem 13:2285-2314

22. Blaser HU, Jalett HP, Wiehl J (1991) Enantioselective hydrogenation of alphaketoesters with chinchona-modified platinum catalysts-Effect of acidic and basic solvents and additives. J Mol Catal 68:215-222

23. LeBlond C, Wang J, Liu J, Andrews AT, Sun YK (1999) Highly enantioselective heterogeneously catalyzed hydrogenation of $a$-ketoesters under mild conditions. J Am Chem Soc 121:4920-4921

24. Schoemaker HE, Mink D, Wubbolts MG (2003) Dispelling the mythsBiocatalysis in industrial synthesis. Science 299:1694-1697

25. Rollin JA, Tamb TK, Zhang PYH (2013) New biotechnology paradigm: Cellfree biosystems for biomanufacturing. Green Chem 15:1708-1719

26. Schmid A, Dordick JS, Hauer B, Kiener A, Wubbolts M, Witholt B (2001) Industrial biocatalysis today and tomorrow. Nature 409:258-268

27. Bai YL, Yang ST (2005) Biotransformation of (R)-2-hydeoxy-4-phenylbutyric acid be D-lactate dehydrogenase and Candida boidinii cells containing formate dehydrogenase coimmbolized in a fibrous bed bioreactor. Biotechnol Bioeng 92:137-146

28. Luetz S, Giver L, Lalonde J (2008) Engineered enzymes for chemical production. Biotechnol Bioeng 101:647-653

29. Behrens GA, Hummel A, Padhi SK, Schaetzle S, Bornscheuer UT (2011) Discovery and protein engineering of biocatalysts for organic synthesis. Adv Synth Catal 353:2191-2215

30. Bommarius AS, Blum JK, Abrahamson MJ (2011) Status of protein engineering for biocatalysts: how to design an industrially useful biocatalyst. Curr Opin Chem Biol 15:194-200

31. Bornscheuer UT, Huisman GW, Kazlauskas RJ, Lutz S, Moore JC, Robins K (2012) Engineering the third wave of biocatalysis. Nature 485:185-194

32. Davids T, Schmidt M, Boettcher D, Bornscheuer UT (2013) Strategies for the discovery and engineering of enzymes for biocatalysis. Curr Opin Chem Biol 17:215-220

33. Oda S, Ohta H (1992) Microbial transformation on interface between hydrophilic carriers and hydrophobic organic solvents. Biosci Biotechnol Biochem 56:2041-2045

34. Oda S, Inada Y, Kobayashi A, Ohta H (1998) Production of ethyl (R)-2hydroxy-4-phenylbutanoate via reduction of ethyl 2-oxo-4-phenylbutanoate in an interface bioreactor. Biosci Biotechnol Biochem 62:1762-1767

35. de Lacerda PSB, Ribeiro JB, Leite SGF, Ferrara MA, Coelho RB, Bon EPS, da Silva Lima EL, Antunes OAC (2006) Microbial reduction of ethyl 2-oxo-4phenylbutyrate. Searching for R-enantioselectivity. New access to the enalapril like ACE inhibitors. Tetrahedron Asymmetry 17:1186-1188

36. Chadha A, Manohar M, Soundararajan T, Lokeswari TS (1996) Asymmetric reduction of 2-oxo-4-phenylbutanoic acid ethyl ester by Daucus carota cell cultures. Tetrahedron Asymmetry 7:1571-1572

37. Chen $Y Z$, Lin $H, X u X Y$, Xia SW, Wang LX (2008) Preparation the key intermediate of angiotensin-converting enzyme (ACE) inhibitors: High enantioselective production of ethyl (R)-2-hydeoxy-4-phenylbutyrate with Candida boidinii CIOC21. Adv Synth Catal 350:426-430

38. He CM, Chang DL, Zhang J (2008) Asymmetric reduction of substituted $\alpha$ and $\beta$-ketoesters by Bacillus pumilus Phe-C3. Tetrahedron Asymmetry 19:1347-1351

39. Dao DH, Okamura M, Akasaka T, Kawai Y, Hida K, Ohno A (1998) Stereochemical control in microbial reduction. Part 31: Reduction of alkyl 2oxo-4-arylbutyrates by baker's yeast under selected reaction conditions. Tetrahedron Asymmetry 9:2725-2737

40. Ni Y, Xu JH (2012) Biocatalytic ketone reduction: a green and efficient access to enantiopure alcohols. Biotechnol Adv 30:1279-1288

41. Nakamura K, Yamanaka R, Matsuda T, Harada T (2003) Recent developments in asymmetric reduction of ketones with biocatalysts. Tetrahedron Asymmetry 14:2659-2681

42. Xie Y, Xu JH, Lu WY, Lin GQ (2009) Adzuki bean: a new resource of biocatalyst for asymmetric reduction of aromatic ketones with high stereoselectivity and substrate tolerance. Bioresour Technol 100:2463-2468

43. Rommens JM, lannuzzi MC, Kerem B, Drumm ML, Melmer G, Dean M, Rozmahel R, Cole JL, Kennedy D, Hidaka N (1989) Identification of cystic fibrosis gene: Chromosome walking and jumping. Science 245:1059-1065
44. Qiu JG, Yun M, Wen YZ, Chen LS, Wu LF, Liu WP (2012) Functional identification of two novel genes from Pseudomonas sp. strain HZN6 involved in the catabolism of nicotine. Appl Environ Microbiol 78:2154-2160

45. Zhang JD, Li AT, Yang Y, Xu JH (2010) Sequence analysis and heterologous expression of a new cytochrome P450 monooxygenase from Rhodococcus sp for asymmetric sulfoxidation. Appl Microbiol Biotechnol 85:615-624

46. Zhang J, Yin JG, Hang BJ, Cai S, He J, Zhou SG, Li SP (2012) Cloning of a novel arylamidase gene from Paracoccus sp. strain FLN-7 that hydrolyzes amide pesticides. Appl Environ Microbiol 78:4848-4855

47. Ni Y, Li CX, Zhang J, Shen ND, Bornscheuer UT, Xu JH (2011) Efficient reduction of ethyl 2-oxo-4-phenylbutyrate at $620 \mathrm{~g} / \mathrm{L}$ by a bacterial reductase with broad substrate spectrum. Adv Synth Catal 353:1213-1217

48. Reddy TBK, Thomas AD, Stamatic D, Bertsch J, Isbandi M, Jansson J, Mallajosyula J, Pagani I, Lobos EA, Kyrpides NC (2014) The genomes online database (GOLD) v.5: a metadata management system based on a four level (meta)genome project classification. Nucl Acids Res doi: 10.1093/nar/ gku950

49. Wang $\sqcup$, Li CX, Ni Y, Zhang J, Liu X, Xu JH (2011) Highly efficient synthesis of chiral alcohols with a novel NADH-dependent reductase from Streptomyces coelicolor. Bioresour Technol 102:7023-7028

50. Itoh N, Morihama R, Wang JC, Okada K, Mizuguchi N (1997) Purification and characterization of phenylacetaldeyde reductase from a styrene-assimilating Corynebacterium strain, ST-10. Appl Environ Microbiol 63:3783-3788

51. Makino Y, Dairi T, Itoh N (2007) Engineering the phenylacetaldehyde reductase mutant for improved substrate conversion in the presence of concentrated 2-propanol. Appl Microbiol Biotechnol 77:833-843

52. Itoh N, Isotani K, Nakamura M, Inoue K, Isogai Y, Makino Y (2012) Efficient synthesis of optically pure alcohols by asymmetric hydrogen-transfer biocatalysis: application of engineered enzymes in a 2-propanol-water medium. Appl Microbiol Biotechnol 93:1075-1085

53. Lavandera I, Kern A, Schaffenberger M, Gross J, Glieder A, Glieder A, de Wildeman S, Kroutil W (2008) An exceptionally DMSO-tolerant alcohol dehydrogenase for the stereoselective reduction of ketones. ChemSusChem 1:431-436

54. Kaluzna IA, Andrew AA, Bonilla M, Martzen MR, Stewart JD (2002) Enantioselective reductions of ethyl 2-oxo-4-phenylbutyrate by Saccharomyces cerevisiae dehydrogenases. J Mol Catal B: Enzymatic 17:101-105

55. Kaluzna IA, Matsuda T, Sewell AK, Stewart JD (2004) Systematic investigation of Saccharomyces cerevisiae enzymes catalyzing carbonyl reductions. J Am Chem Soc 126:12827-12832

56. Richter N, Hummel W (2011) Biochemical characterization of a NADPHdependent carbonyl reductase from Neurospora crassa reducing $\alpha$ - and $\beta$ keto esters. Enzyme Microbial Technol 48:472-479

57. Ni Y, Su YN, Li HD, Zhou JY, Sun ZH (2013) Scalable biocatalytic synthesis of optically pure ethyl (R)-2-hydroxy-4-phenylbutyrate using a recombinant $E$. coli with high catalyst yield. J Biotechnol 168:493-498

58. Ma HM, Yang LL, Ni Y, Zhang J, Li CX, Zheng GW, Yang HY, Xu JH (2012) Stereospecific reduction of methyl o-chlorobenzoylformate at $300 \mathrm{~g} \cdot \mathrm{L}^{-1}$ without additional cofactor using a carbonyl reductase mined from Candida glabrata. Adv Synth Catal 354:1764-1772

59. Shen ND, Ni Y, Ma HM, Wang LJ, Li CX, Zheng GW, Zhang J, Xu JH (2012) Efficient synthesis of a chiral precursor for angiotensin-converting enzyme (ACE) inhibitors in high space-time yield by a new reductase without external cofactors. Org Lett 14:1982-1985

60. Yun HD, Choi HL, Fadnavis NW, Kim BG (2005) Stereosepecific synthesis of (R)-2-hydroxy carboxylic acids using recombinant E. coli BL21 overexpressing YiaE from Escherichia coli K12 and glucose dehydrogenase from Bacillus subtilis. Biotechnol Prog 21:366-371

61. Persson B, Kallberg Y, Bray JE, Bruford E, Dellaporta SL, Favia AD, Duarte RG, Jörnvall H, Kavanagh KL, Kedishvili N, Kisiela M, Maser E, Mindnich R, Orchard S, Penning TM, Thornton JM, Adamski J, Oppermann U (2009) The SDR (short-chain dehydrogenase/reductase and related enzymes) nomenclature initiative. Chemico-Biol Interact 178:94-98

62. Hedlund J, Jörnvall H, Persson B (2010) Subdivision of the MDR superfamily of medium chain dehydrogenases/reductases through iterative hidden Markov model refinement. BMC Bioinformatics 11:534-549

63. Hyndman D, Bauman DR, Heredia W, Penning M (2003) The aldo-keto reductase superfamily homepage. Chemico-Biol Interact 143-144:621-631

64. Hwang CC, Chang YH, Hsu CN, Hsu HH, Li CW, Pon HI (2005) Mechanistic roles of Ser-114, Tyr-155, and Lys-159 in 3-hydroxysteroid dehydrogenase/carbonyl reductase from Comamonas testosteroni. J Biol Chem 280:3522-3528 
65. Ehrensberger AH, Wilson DK (2004) Structural and catalytic diversity in the two family 11 aldo-keto reductases. J Mol Biol 337:661-673

66. Robert X, Gouet P (2014) Deciphering key features in protein structures with the new ENDscript server. Nucl Acid Res 42:W320-W324

67. Moore JC, Pollard DJ, Kosjek B, Devine PN (2007) Advances in the enzymatic reduction of ketones. Acc Chem Res 40:1412-1419

68. Zhao HM, van der Donk WA (2003) Regeneration of cofactors for use in biocatalysis. Curr Opin Biotechnol 14:583-589

69. Huisman GW, Liang J, Krebber A (2010) Practical chiral alcohol manufacture using ketoreductases. Curr Opin Chem Biol 14:122-129

Submit your manuscript to a SpringerOpen ${ }^{\circ}$ journal and benefit from:

- Convenient online submission

- Rigorous peer review

- Immediate publication on acceptance

- Open access: articles freely available online

- High visibility within the field

- Retaining the copyright to your article

Submit your next manuscript at $>$ springeropen.com 